\title{
DIÁRIOS DE TESTEMUNHAS: DAS MEMÓRIAS SUBJETIVAS AOS PRODUTOS MIDIÁTICOS
}

\author{
Diaries of testimonies: from subjective memories to media products
}

Diarios de testimonios: de las memorias subjetivas a los productos mediaticos

Barbara Heller

Docente e pesquisadora do PPGCOM da Universidade Paulista (Unip)

b.heller.sp@gmail.com

Herom Vargas

Docente e pesquisador do PósCom da Universidade Metodista de São Paulo (UMESP)

heromvargas50@gmail.com

\section{Resumo}

Neste artigo analisamos três narrativas de memórias veiculadas no Brasil por importantes editoras comerciais: A guerra não tem rosto de mulher, de Svetlana Aleksiévitch, Eu sou Malala, de Malala Yousafzai e Christina Lamb e Diários de Berlim, de Marie Vassiltchikov. Problematizamos os conceitos de trauma, testemunho, memória e verdade, com SeligmannSilva, Pollak e Sarlo, e o gênero textual diário, com Lejeune e Duarte. As escolhas visuais das capas são pensadas dentro das lógicas editoriais que transformam a subjetividade dos diários em atraentes produtos comerciais. Os resultados apontam para a diversidade de tipos de testemunho, o alargamento do gênero textual diário e a organicidade das capas com as narrativas que embalam.

Palavras-chave: Diário. Memória. Testemunha.

\begin{abstract}
In this article we analyze three narratives of memories conveyed in Brazil by important commercial publishing houses: A guerra não tem rosto de mulher, by Svetlana Aleksiévitch, Eu sou Malala, by Malala Yousafzai e Christina Lamb, and Diários de Berlim, by Marie Vassiltchikov. We discuss the concepts of trauma, testimony, memory and truth, with Seligmann-Silva, Pollak and Sarlo, and the textual genre diary, with Lejeune and Duarte. The visual choices of the covers are thought within the editorial logic that transforms the subjectivity of the diaries into attractive commercial products. The results point to the diversity of types of testimony, the widening of the textual genre diary and the organicity of the covers with the narratives that they pack.
\end{abstract}

Key words: Diary. Memory. Testimony.

\section{Resumen}

En este artículo analizamos tres relatos de memorias vehiculados en Brasil por importantes editoriales comerciales: A guerra não tem rosto de mulher, de Svetlana Aleksiévitch, Eu sou Malala, de Malala Yousafzai e Christina Lamb e Diários de Berlim, de Marie Vassiltchikov. Problematizamos los conceptos de trauma, testimonio, memoria y verdad, con Seligmann- 
Silva, Pollak y Sarlo, y el género textual diario, con Lejeune y Duarte. Las opciones visuales de las cubiertas de libros están pensadas dentro de la lógica editorial que transforma la subjetividad de los diarios en productos comerciales atractivos. Los resultados apuntan a la diversidad de tipos de testimonios, la ampliación del género textual diario y la organicidad de las cubiertas de libros con las narrativas que contienen.

Palabras clave: Diario. Memoria. Testimonio.

\section{INTRODUÇÃO}

Em 2013, ano em que dois dos três livros em análise neste artigo foram publicados $-A$ guerra não tem rosto de mulher, de Svetlana Aleksiévitch, e Eu, Malala, de Malala Yousafzai e Christina Lamb, ambos pela Companhia das Letras - o mercado editorial brasileiro cresceu significativamente em relação ao ano anterior. Conforme informa o Sindicato Nacional dos Editores de Livros (SNEL), o aumento nominal foi de 7,52\%. O maior volume de vendas se deu no setor de Obras Gerais, cujo maior comprador é o governo federal, seguido pelo de religiosos. Se, por um lado, ainda segundo o SNEL, houve crescimento de 8,29\% em número de títulos, reduziu-se a quantidade de exemplares. A conclusão a que chegaram os responsáveis pelo relatório é a de que esse "cenário demonstra a preocupação das editoras em oferecer uma gama mais diversificada de títulos, buscando aumentar as chances de encontrar livros vendedores"1.

Essa hipótese permite conjecturar por que uma mesma editora, a Companhia das Letras, publica em um único ano duas obras de cunho autobiográfico e a Boitempo, um terceiro, dois anos mais tarde apenas. Trata-se, talvez, da percepção dos editores ou dos responsáveis pelos respectivos setores comerciais de que narrativas com forte presença de tom testemunhal teriam boa chance de vendas e, assim, valeria a pena investir em novos títulos.

Pode-se dizer que se formou no Brasil um público leitor diverso, interessado primeiramente por obras de autoajuda, seguido depois por outras categorias, como biografias de celebridades, além dos de memória². Otávio Marques da Costa, publisher da Companhia das Letras em 2017, afirma: "Sempre publicamos biografias com sucesso, as nacionais,

\footnotetext{
1 Disponível em: https://snel.org.br/setor-editorial-cresce-752-em-2013-e-preco-medio-constante-do-livrocontinua-a-cair/ Acesso em: 27 mar. 2019.

2 Segundo dados da Nielsen Bookscan, instituição de matriz britânica, que realiza pesquisas no mercado livreiro no Brasil desde 2013, os livros de memórias lançados em 2017 cresceram 23,4\% de faturamento em relação ao ano anterior. Disponível em: https://www.pagina3.com.br/cultura/2018/jan/13/1/livros-de-memorias-fazemvendas-de-biografias-dispararem-no-pais Acesso em: 02 abr. 20020.
} 
sobretudo. Temos realmente notado um aumento de interesse no gênero, mas especialmente nesses livros de memórias, o que era menos usual no Brasil"’3.

Transformados em produtos editoriais bem cuidados, operam com os mais variados sentidos do corpo e da mente: visual, porque apresentam capas e contracapas com design atraente; tátil, porque a gramatura das páginas e das capas agradam ao toque; emocional, porque contam histórias de vida permeadas de ameaças e superação; intelectual, porque informam dados até então pouco conhecidos de eventos e de personagens, entre outros.

Voltados para um consumo amplo, tais produtos transformam a subjetividade dos testemunhos em apelo mercadológico. Uma das razões para isso é o fato de tenderem a consolidar uma "verdade" apoiada na força do discurso de memória dos sujeitos que narram. Em segundo lugar, há um importante trabalho editorial (traduções, notas de rodapé, comentários, prólogos, imagens, diagramação, capa) elementos que comparecem no objeto livro, mas que não faziam parte do original criado pelo autor.

Para os limites estreitos deste artigo, quatro critérios definiram a seleção das obras em análise, embora reconheçamos a existência de muitas outras, igualmente importantes, mas com menor aderência aos nossos propósitos: 1. Tratam de eventos traumáticos; 2. Apresentam maneiras distintas de configurar o gênero textual diário; 3. Foram publicados por editoras comerciais, com significativa participação no mercado de livros no Brasil; 4. São autobiográficos, isto é, escritos em $1^{\mathrm{a}}$ pessoa.

$\mathrm{O}$ artigo começa por explicitar o caráter comercial e cultural do livro, composto por uma narrativa impressa em papel, pela capa e contracapa, produzido por uma casa editorial e colocado no mercado. Depois, resume o enredo de cada obra e descreve os componentes visuais das capas e contracapas em diálogo com as narrativas. No terceiro item, cuida do silenciamento a que muitas vezes as testemunhas se impõem, especialmente quando passam por situações traumáticas. Por fim, discute o gênero diário.

\section{LIVRO COM PRODUTO NO MERCADO CULTURAL}

A reflexão aqui desenvolvida parte do princípio de que as integridades física e simbólica no livro são inseparáveis, desde sua origem. Ao longo do século XIX, no mundo ocidental, os processos industriais de produção e a expansão da alfabetização tornaram-no um objeto complexo, uma vez que reúne informação, cultura, narrativa, experiência estética e

3 Disponível em: https://www.pagina3.com.br/cultura/2018/jan/13/1/livros-de-memorias-fazem-vendas-debiografias-dispararem-no-pais Acesso em: 02 abr. 20020. 
status social. Tornado objeto de consumo e de desejo, o livro, assim como qualquer produto cultural no mercado, sujeita sua materialidade (embalagem, capa, gramatura das folhas etc.) às demandas publicitárias (CALDAS, 2009: McCRAKEN, 2003).

No caso do livro, a capa é a sua embalagem e, por isso, não pode ser descartada, como ocorre com outros objetos da sociedade de consumo. Além de fazer parte da lógica publicitária, a capa é o primeiro espaço visual de contato entre livro e leitor; por meio dela, seus elementos essenciais (autor, título, editora etc.) ficam imediatamente acessíveis ao consumidor. Essas características demarcam a capa, portanto, como forte elemento mediador no consumo: "Enquanto face visível do livro, a capa assume um papel privilegiado na comunicação com o público e, consequentemente, constitui um veículo privilegiado de promoção comercial” (CARVALHO, 2008, p. 13).

Para este artigo, os elementos da linguagem visual e sua composição no espaço da capa (DONDIS, 2003) são tomados como constituintes essenciais dos livros e determinantes dos respectivos projetos editoriais. Capa e contracapa serão observadas em diálogo orgânico com a narrativa e com as respectivas demandas comerciais.

\section{ENREDOS E CAPAS}

\subsection{A guerra não tem rosto de mulher}

Em A guerra não tem rosto de mulher, Svetlana Aléksiévitch gravou e anotou durante dois anos, in loco, centenas de entrevistas de soldadas soviéticas que, 50 anos antes, combateram na II Guerra Mundial defendendo a então União das Repúblicas Socialistas Soviéticas (URSS). Os sentimentos das ex-combatentes, suas guerras individuais, "unir o discurso da rua e da literatura", "ser uma historiadora da alma" e falar "do passado com a língua de hoje" (ALEKSIÉVITCH, 2016, p. 18-19) foram algumas das tarefas a que a autora, vencedora do Prêmio Nobel de literatura em 2015, se propôs. Publicado na década de 1980 em sua língua original e no Brasil em 2016, pela Companhia das Letras, com tradução de Cecília Rosas, o livro não apresenta uma narrativa tradicional com enredo linear. A autora bielo-russa

não se preocupa tampouco em sincronizar esse espaço com o tempo na perspectiva clássica [...], já que os tempos com os quais trabalha são fluídos porque tecidos pela matéria tênue da memória dos depoentes, com seus silêncios, "esquecimentos" sociais [...] e lembranças que irrompem no momento em que menos se espera (HELLER; MARTINEZ, 2020, p. 3). 
Muitas vezes isoladas e abandonadas no regresso devido às mutilações no corpo e ao estigma, relataram suas histórias pessoais depois de décadas de silêncio, como descreve a autora:

Entendo agora a solidão da pessoa que volta de lá. É como se viesse de outro planeta ou do além. Ela tem o conhecimento de algo que os outros não têm, e só é possível conquistá-lo ali, perto da morte. Quando tenta transformar isso em palavras, tem a sensação de uma catástrofe. A pessoa se cala (ALEKSIÉVITCH, 2016, p. 17).

Ao concluir a obra, o leitor tem em mãos uma reconstrução do que foi a II Guerra Mundial para as mulheres soviéticas que foram voluntariamente ao front, contrariando, na maior parte das vezes, seus familiares.

A capa (Fig. 1) é composta por uma foto em tons de vermelho com o rosto de uma mulher à esquerda. Em certo ponto, a imagem é "arrastada" para a direita, formando linhas horizontais sobre as quais estão o título, o nome da autora e a informação da premiação, tudo grafado em branco, provocando alto contraste para melhor leitura. Na contracapa (Fig. 2), como em um espelhamento, as posições se invertem, com o rosto de outra mulher à direita e, à esquerda, a reprodução de um trecho da narrativa, seguida por um comentário publicitário, com vários adjetivos, ambos escritos na cor branca. Como no enredo, a figura feminina ganha destaque e a violência da guerra é traduzida na cor quente que domina a área visual.

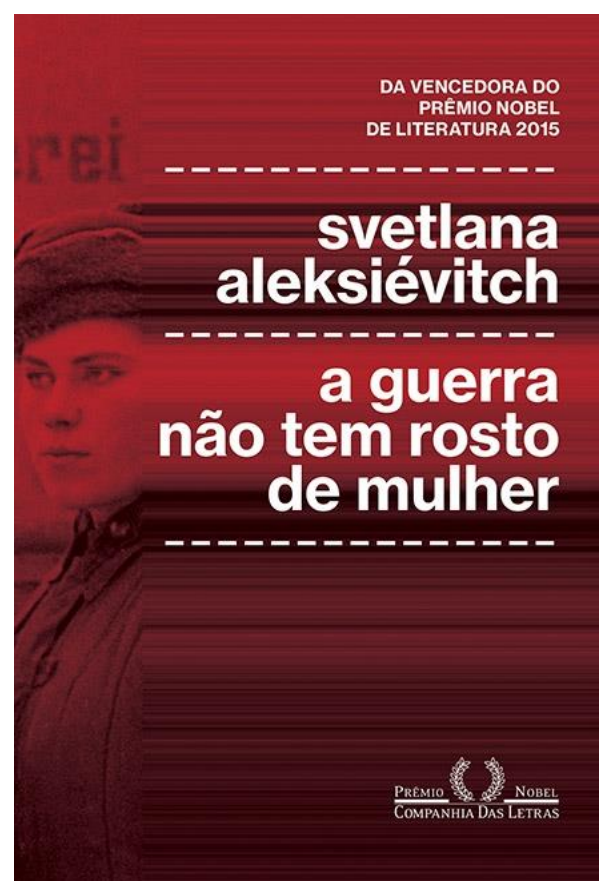

Figura 1 - Capa de A guerra não tem rosto de mulher

Fonte: Internet 


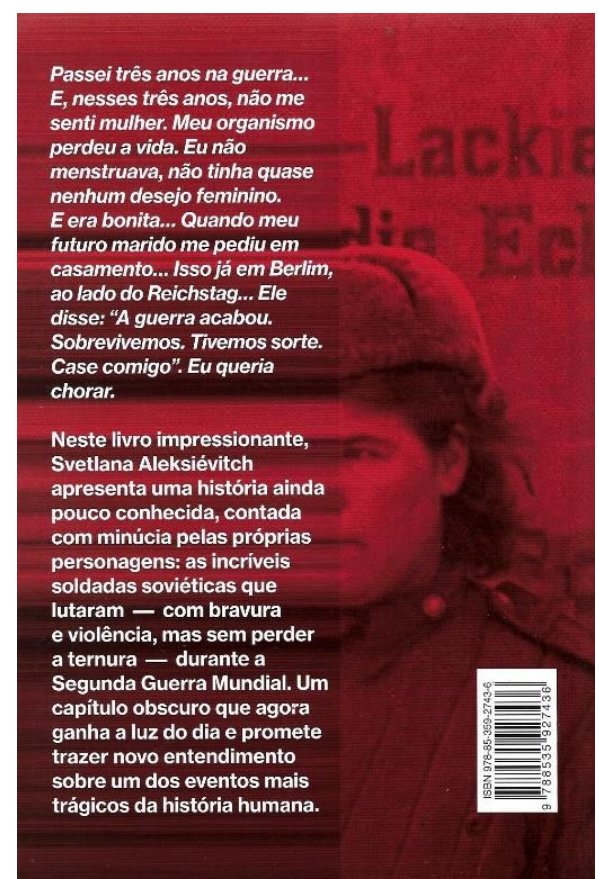

Figura 2 - Contracapa de A guerra não tem rosto de mulher Fonte: Internet

\subsection{Eu sou Malala}

Em 2013, a Companhia das Letras publicou Eu sou Malala, um ano antes de a paquistanesa Malala Yousafzai receber o Prêmio Nobel da Paz por defender o direito à educação e à igualdade de gêneros em seu país. Vítima de violento atentado cometido pelo Talibã em 2012, aos 15 anos, em Swat, no Paquistão, Malala tornou-se figura internacionalmente conhecida. Sua excepcional recuperação, os antecedentes do dia em que quase morreu e seu exílio na Inglaterra, entre outros eventos, são narrados nessa obra que, diferentemente de A guerra não tem rosto de mulher, foi produzida sob encomenda. Não à toa, a autoria é dividida com Christina Lamb, jornalista internacionalmente premiada, correspondente no Paquistão e no Afeganistão desde 1987. O relato no seu blog conta como se deram os primeiros contatos entre as duas:

Tudo começou em janeiro quando um e-mail inesperadamente entrou na minha caixa de entrada com o assunto "Malala Yousafzai".

$[\ldots]$

Boa parte da minha carreira como correspondente internacional foi dedicada a cobrir o Paquistão, o Afeganistão e o Talibã, portanto, eu seguia seu blog no website da BBC em 2009 sobre como era vida de uma estudante no vale de Swat, quando o Talibã assumiu o controle. Eu a admirava por sua 
coragem, arriscando a vida pelo direito de as meninas irem à escola e estava intrigada para encontrá-la ${ }^{4}$.

Tais condições de contrato tornam o livro um gênero híbrido. Há nele jornalismo e biografia, uma vez que as informações que a jornalista colhe a partir dos encontros frequentes por nove meses com Malala, já na Inglaterra, lhe permitem organizar os assuntos em cinco partes, seguidas por glossário, anexos, agradecimentos e informações sobre o Fundo Malala.

Apenas na página 164 , de um total de 342 , o leitor se depara com a informação de como a futura ganhadora do prêmio Nobel começou a escrever seu blog, à qual Christina Lamb se refere. Incentivada por seu pai e por um amigo dele, correspondente da BBC em Peshawar, Malala inaugura suas postagens em 3 de janeiro de 2009 e o encerra no início de março do mesmo ano (YOUSAFZAI; LAMB, 2013). Talvez por influência do Diário de Anne Frank, que leu por recomendação do jornalista da BBC, sempre se refere ao blog como "diário", embora tivesse orientações explícitas do que deveria comentar: "o lado humano da catástrofe que estávamos sofrendo no Swat" (2013, p. 164). Trata-se, portanto, de uma produção motivada fortemente por razões políticas e não pela necessidade espontânea de registrar, sob seus próprios filtros, as mais variadas impressões subjetivas, como costuma ocorrer nos diários que chamaremos, aqui, de "primários" ou "originais".

O livro compõe-se quase exclusivamente dos relatos de Malala sobre sua vida anterior ao atentado, mas nota-se o trabalho da jornalista, uma vez que a tensão é crescente. O clímax ocorre na parte IV, "Entre a vida e a morte" (p. 255). Nas últimas 60 páginas, a narrativa concentra-se nos momentos imediatamente posteriores ao tiro, nos primeiros atendimentos médicos, nas cirurgias, nas negociações políticas e financeiras para seu traslado ao Hospital Queen Elisabeth, na Inglaterra. O epílogo trata de sua adaptação no novo país, a recuperação dos movimentos faciais e o reencontro com sua família.

\footnotetext{
${ }^{4}$ Todas as traduções foram feitas pelos autores. No original: It all started in January when an email unexpectedly dropped into my inbox with the subject "Malala Yousafzai".

$[\ldots]$

Much of my career as a foreign correspondent has been spent covering Pakistan, Afghanistan and the Taliban, so I'd followed her blog on the BBC website in 2009 about life as a schoolgirl in the Swat valley when the Taliban took over. I was in awe of her bravery, risking her life for the right of girls to go to school, and of course intrigued to meet her. Disponível em: http://christinalamb.net/articles/my-year-with-malala.html Acesso: 29 mar. 2020.
} 


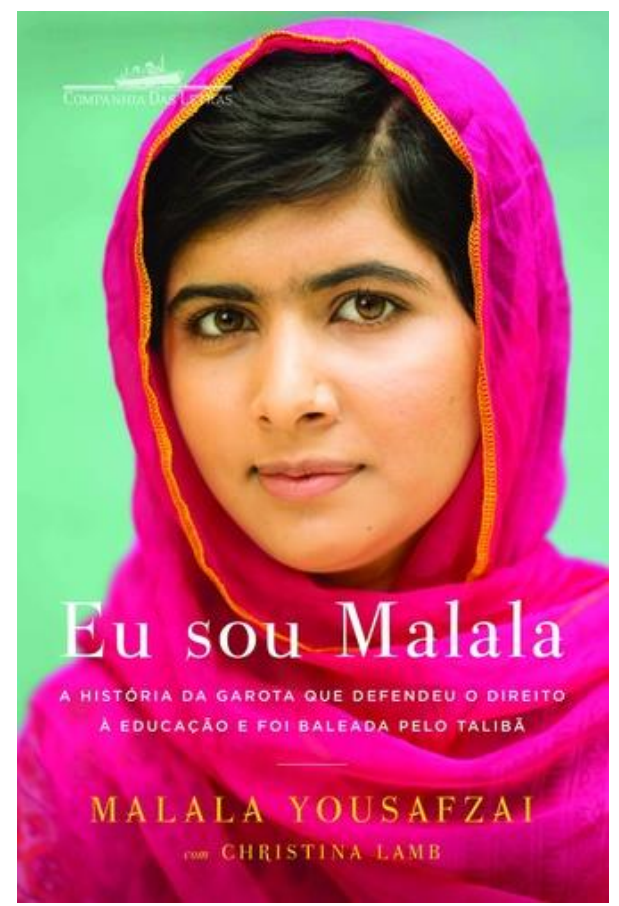

Figura 3 - Capa de Eu sou Malala Fonte: Internet

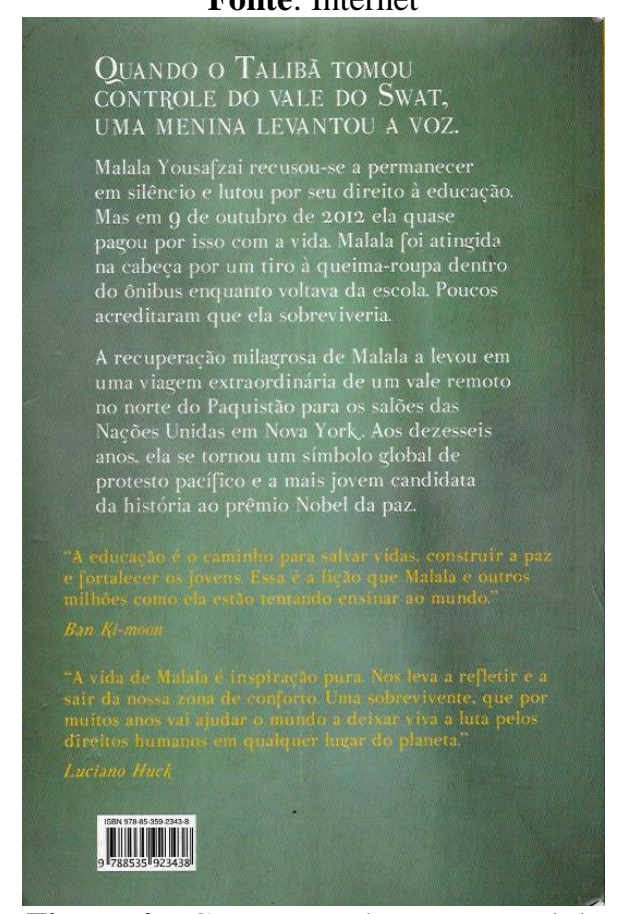

Figura 4 - Contracapa de Eu sou Malala Fonte: Internet

Em grande medida, a capa (Fig. 3) acompanha visualmente os apelos de um produto editorial construído para público amplo: é simples, simétrica e com poucos pontos de tensão ou aguçamento visual (DONDIS, 2003). Mais da metade de sua área é tomada pelo rosto de Malala, com olhos direcionados para a câmera, como se estivesse falando com o leitor com intimidade. No terço inferior estão título, subtítulo e nomes das autoras centralizados. O 
contraste entre a cor roxa de seu véu e o fundo verde-claro chama a atenção. Na contracapa (Fig. 4), sob um fundo verde levemente mais escuro, encontram-se três pequenos textos: um típico de apresentação da personagem com tom de exaltação, escrito em branco, e dois pequenos, abaixo, grafados em amarelo, com pouco contraste, que transcrevem depoimentos sobre Malala de Ban Ki-moon, diplomata sul-coreano então secretário-geral da Organização das Nações Unidas (ONU), e do apresentador de TV, Luciano Huck. Arriscamos compreender a presença dos enunciados de Huck pelo fato de ser celebridade e, assim, chamar a atenção de um público mais aderente aos programas televisivos que ao livro.

\subsection{Diários de Berlim (1940-1945)}

Talvez o menos conhecido dos três títulos, a obra de Marie Vassiltchikov é o que se considera diário na acepção mais comum do termo: uma espécie de arquivo de nossas vidas, assim como gavetas que guardam bilhetes, passagens, mapas de lugares visitados ou a visitar etc. No entanto, como lembra Artières (1998, p. 11), em um "diário íntimo, registramos apenas alguns acontecimentos, omitimos outros; às vezes, quando relemos nosso diário, acrescentamos coisas ou corrigimos aquela primeira versão".

Aristocrata nascida na Russa, a autora refugiou-se desde 1919 na Lituânia independente (1918-1940), onde seu pai dispunha de propriedades. Graças à revisão do pacto nazista-soviético, com a eclosão da II Guerra Mundial, o país que a abrigara até então tornarase novamente dominado pelos soviéticos, condição que colocava seus familiares novamente em perigo.

Quando a II Guerra Mundial eclodiu, Marie Vassiltchikov encontrava-se com sua segunda irmã na Silésia (Alemanha) e o resto da família achava-se espalhado entre Roma, Lituânia e Suíça. Como explica no Prefácio escrito por seu irmão George Vassiltchikov, desde a depressão econômica do começo dos anos 1930, "era praticamente impossível para um estrangeiro conseguir autorização para trabalhar em qualquer uma das democracias do Ocidente" (VASSILTCHIKOV, 2015, p. 17-18), mas por saber inglês fluentemente, conseguiu trabalho no Serviço de Rádio e, depois, no Departamento de Informações do Ministério do Exterior, em Berlim. Foi nesse ambiente que conheceu "um dos núcleos duros dos resistentes antinazistas que viriam se envolver ativamente no que passou para a história como “Conspiração de 20 de julho"” (2015, p. 18).

A obra de Vassiltchikov é considerada o único "diário que dá um testemunho ocular do que aconteceu" (2015, p. 18). Ainda segundo o prefaciador, a autora escrevia 
compulsivamente, mas "apenas as narrativas mais longas, como a dos bombardeios em Berlim em novembro de 1943, foram escritas ex post facto, embora imediatamente depois dos eventos" (2015, p. 18). As páginas datilografadas eram guardadas "em um arquivo em seu escritório, escondidas entre relatórios oficiais" (2015, p. 18-19), como se soubesse o valor que adquiririam em um futuro próximo.

Retomamos o pensamento do já mencionado Artières (1998, p. 11), para quem

Escrever um diário, guardar papéis, assim como escrever urna autobiografia, são práticas que participam mais daquilo que Foucault chamava a preocupação com o eu.

Arquivar a própria vida é se pôr no espelho, é contrapor à imagem social, a imagem íntima de si próprio, e nesse sentido o arquivamento do eu é uma prática de construção de si mesmo e de resistência.

A versão definitiva do diário ficou pronta apenas uma semana antes da morte da autora, o que mostra suas várias interferências ao longo da vida. Não fora seu irmão, talvez o resultado final fosse muito diverso, uma vez que foi ele quem insistiu para que o tornasse público em 1976. Pequenos trechos foram suprimidos ainda por ela, mas boa parte da edição foi feita pelo irmão e pela filha de Marie: organização definitiva, extensas notas de rodapé para explicar os personagens citados, introdução, acréscimo de imagens, epílogo, posfácio, índice onomástico e crédito das imagens.

Trata-se de um livro que ultrapassa os limites que caracterizam um diário, apesar de essa palavra constar em seu título. A começar, a autora realiza diversas interferências ao longo dos anos para adequar seus originais às publicações futuras. Antes da impressão final, seu irmão consulta bibliotecas e a internet para explicar, nas extensas e inúmeras notas de rodapé, quem é quem e a importância dos eventos citados no corpo do texto. Também entrevista pessoas e, por fim, agradece a experiência profissional dos editores (2015, p. 2223). Com tantos agentes envolvidos na produção da obra, é certo que o resultado final é bastante diverso dos textos originais.

Nesse livro, o trabalho gráfico da capa revelou-se mais detalhado, provavelmente para acompanhar a construção mais intrincada da narrativa. A capa (Fig. 5), mesmo tendo uma simetria bilateral clara, que facilita a percepção, produz algumas tensões visuais. Uma está no contraste entre cores da parte superior e da inferior, com maior peso da imagem de Marie quando jovem; a segunda tensão aparece nas linhas diagonais que trazem título e subtítulo da obra e o nome da autora; em terceiro, uma sutileza no contraste dos olhares dos personagens 
para demonstrar suas diferenças também presentes no enredo. Na contracapa (Fig. 6), uma foto em preto e branco bastante granulada mostra Adolf Hitler sendo cumprimentado e, sobre sua imagem, a inserção de uma cruz vermelha como que a indicar um alvo ou alguém que deve desaparecer. No terço inferior, há um comentário do crítico literário Antonio Candido, importante acadêmico brasileiro, cujo depoimento sobre a obra busca conferir-lhe valor erudito.

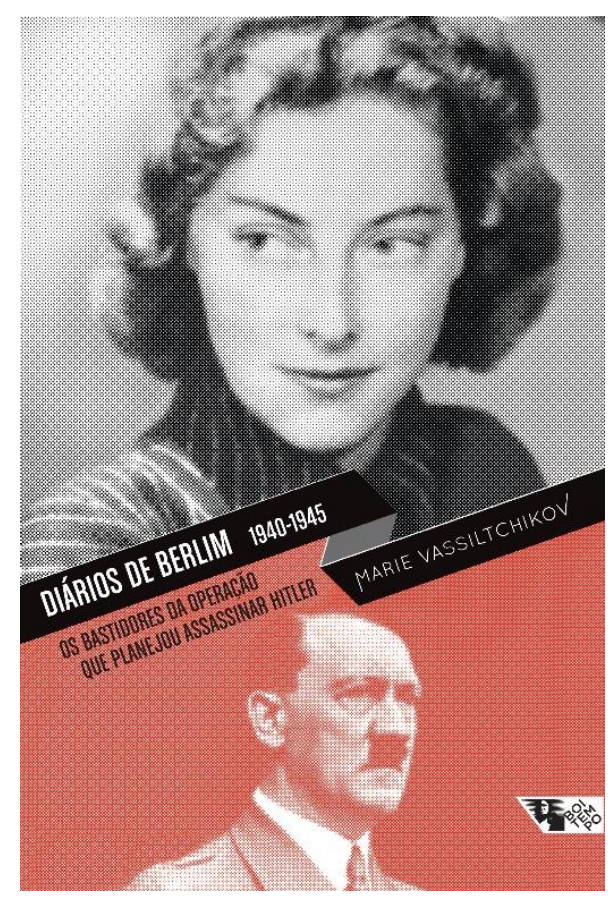

Figura 5 - Capa de Diários de Berlim Fonte: Internet

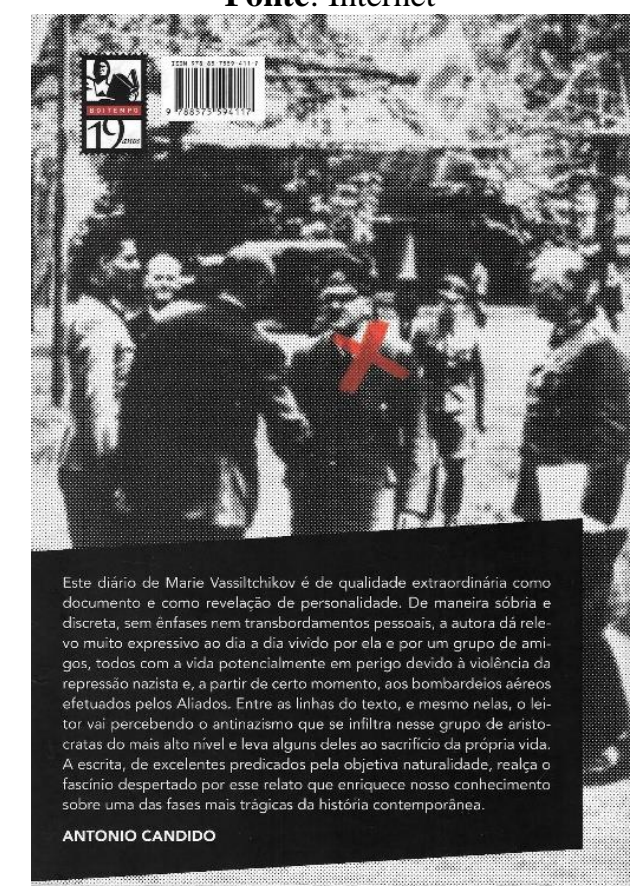

Figura 6 - Contracapa de Diários de Berlim Fonte: Internet 


\title{
4 TRAUMA, NARRATIVA E SILENCIAMENTO
}

Seligmann-Silva (2008, p. 66) afirma, a partir da leitura da obra de Primo Levi É isto um homem?, que narrar o trauma adquire, em um primeiro momento, "o sentido de renascer". Trata-se de uma tentativa de a testemunha criar vínculo com seu interlocutor para que seja ouvida. A experiência dos traumatizados de grandes catástrofes históricas, como a II Guerra Mundial, mostra que os horrores que contavam, no lugar de estabelecer laços de solidariedade e de empatia, afastavam os ouvintes:

\begin{abstract}
A outridade do sobrevivente é vista aí como insuperável. A narrativa teria, portanto, dentre os motivos que a tornavam elementar e absolutamente necessária, este desafio de estabelecer uma ponte com "os outros", de conseguir resgatar o sobrevivente do sítio da outridade, de romper com os muros do Lager ${ }^{5}$ (SELIGMANN-SILVA, 2008, p. 66).
\end{abstract}

Tal tarefa é, muitas vezes, insuportável para a testemunha, porque a faz reviver a experiência do terror. Além disso, a frequente recusa de os outros ouvirem tais narrativas reforça nela o sentimento de não mais pertencer ao mundo que lhe foi roubado. Nada mais a conecta à sua casa; o ambiente que era seu, deixou de lhe ser familiar.

Assim como Seligmann-Silva, que escolheu o plural ao se referir às "catástrofes históricas" em seu texto, as narrativas traumáticas de que tratamos agora também são várias. Para tratar delas, não é mais possível ficar apenas na memória individual, mas na sua "componente coletiva", uma vez que ultrapassam quem as viveu. "A memória do trauma é sempre uma busca de compromisso entre o trabalho de memória individual e outro construído pela sociedade" (SELIGMANN-SILVA, 2008, p. 67).

Há que se tomar cuidado quando mencionamos a ideia de coletivo para se pensar questões da memória. A memória coletiva, tal qual formulou Maurice Halbwachs em $1945^{6}$, é fixa e moldada oficialmente. Como explica Elza Peralta (2007, p. 6), para ele, "a identidade coletiva precede a memória, determinando aquela o conteúdo desta, considerando, portanto, que a identidade é estável e coerente", como se não houvesse "tensão dialética entre a memória individual e a construção social do passado".

Foi apenas no final da década de 1970 que o termo memória coletiva foi substituído por memória social. A partir de então, o passado deixou de ser entendido como imutável e

\footnotetext{
${ }^{5}$ Lager, palavra alemã, significa "campo de concentração" em português.

6 Maurice Halbwachs foi vítima do nazifascismo e morreu em campo de concentração. Sua obra Memória coletiva foi publicada postumamente, em 1950.
} 
fixo, mas seu contrário: instável e conflituoso. As disputas em torno da memória justificam as inúmeras versões sobre eventos considerados históricos e documentados e a desconfiança da subjetividade de suas testemunhas.

As situações traumáticas são muitas e variadas, conforme os locais e épocas em que ocorrem. Em cada uma, o testemunho pode ser uma das poucas maneiras de traduzir sua dimensão. Para compreendermos o testemunho e sua importância, recorremos a Beatriz Sarlo (2007, p. 9), teórica argentina que defende a subjetividade como um "ícone da Verdade"7. Para ela, a história acadêmica despreza as testemunhas, reforça o princípio organizador de eventos do passado e impõe certezas no lugar de hipóteses e dúvidas.

Com os desdobramentos das pesquisas com a tônica dos Estudos Culturais, o conceito de testemunho passou a englobar os sobreviventes de outras guerras, de genocídios diversos e também a qualificar "o discurso, ou contradiscurso das mulheres, das minorias, dos soropositivos" (SELIGMANN-SILVA, 2005, p. 86). É assim que compreendemos a defesa de Sarlo pelos "sujeitos normais" e "marginais" como testemunhos: "relativamente ignorados em outros métodos de narração do passado, demandam novas exigências do método e tendem à escuta sistemática dos 'discursos da memória': diários, cartas, conselhos, orações" (SARLO, 2005, p. 17).

É preciso lembrar, também, que o testemunho tem duplo sentido, ambos importantes e complementares para os estudos da memória. Em uma primeira acepção, testemunhar é presenciar a cena pessoalmente, mas vista de fora, como é recorrente nos documentários nazifascistas que mostram cidadãos que assistem ao aprisionamento dos "indesejáveis" das janelas de suas casas. Embora não estejam sofrendo a ação da violência diretamente, serão capazes de relatá-la décadas à frente e ainda afirmarão: "Eu estava lá... Vi com meus próprios olhos". Uma segunda acepção de testemunha é de quem viveu pessoalmente a experiência, cujas consequências foram sentidas no corpo. Assim como o primeiro tipo que acompanhou de longe, também será capaz de pronunciar: "Eu estava lá... Senti na própria pele".

Michael Pollak também se debruçou sobre memória social e silenciamento. Sociólogo nascido na Áustria em 1948, pesquisou os campos de concentração e entrevistou sobreviventes. Seu contato direto com esse grupo social o fez formular algumas hipóteses sobre o silenciamento que muitos manifestaram quando instados a narrar os traumas sofridos: evitar mal-estar "com aqueles que, de perto ou de longe, ao menos sob a forma de

\footnotetext{
7 A autora grafa com $\mathrm{V}$ maiúscula a palavra verdade, o que justifica a opção de fazermos o mesmo procedimento.
} 
consentimento tácito, assistiram à sua deportação" (POLLAK, 1989, p. 5); “encontrar uma escuta [...] e poupar os filhos de crescer na lembrança das feridas dos pais” $(1989$, p. 6).

Para o autor, muitas narrativas dos sobreviventes, quando reveladas, são compreendidas como "subterrâneas", pois se opõem às memórias instituídas pelo Estado, as “enquadradas". Percebemos, a partir dessas duas categorias de memória - "subterrâneas" e "enquadradas" - que Pollak entende a memória social como uma forma de manifestação dos sujeitos que ora se sujeitam ao Estado, ora se opõem a ele. Dependendo de suas condições emocionais e da segurança física, modulam suas memórias, tornando-as muito mais instáveis do que desejaria qualquer Estado.

Nem sempre uma testemunha repete narrativas iguais sobre um mesmo evento. A memória é um “campo de conflitos" (SARLO, 2007, p. 20) e a

fronteira entre o dizível e indizível, o confessável e o inconfessável, separa, em nossos tempos, uma memória coletiva subterrânea da sociedade civil dominada ou de grupos específicos, de uma memória coletiva organizada que resume a imagem que uma sociedade majoritária ou o Estado desejam passar e impor (POLLAK, 1989, p. 8).

Em A guerra não tem rosto de mulher, de S. Aleksiévitch, encontramos, desde as primeiras páginas, enunciados da autora que explicitam a memória silenciada das combatentes que sofreram os horrores do front na II Guerra Mundial. Esquecidas pelo Estado e frequentemente abandonadas pela família, uma vez que voltaram mutiladas, traumatizadas e envelhecidas para dar início a uma nova família, só deram vazão às suas memórias quando o Estado deixou de ser autoritário e persecutório e, simultaneamente, encontraram uma escuta. É o que mostra a passagem que segue, extraída do capítulo Do diário do livro, uma espécie de prólogo: "Começou a perestróika de Gorbatchóv [...] Comecei a receber dezenas de cartas todos os dias, minhas pastas iam engordando. As pessoas queriam falar... Dizer tudo... Ficaram mais livres e mais sinceras" (ALEKSIÉVITCH, 2016, p. 27). Não à toa, as imagens das duas mulheres na capa e contracapa encontram-se pela metade e rasuradas, como se as mulheres na guerra não tivessem mais suas integridades.

A dificuldade das escolhas das depoentes que comporiam o livro mostra a consciência de Svetlana Aleksiévitch sobre a instabilidade da memória das testemunhas, bem como do apagamento a que estavam submetidas, uma vez que nunca tinham revelado suas histórias. A autora buscava recolher a "história relatada por uma testemunha ou por um participante que 
ninguém notou. [...] Mas as pessoas que contavam não eram apenas testemunhas, menos que tudo testemunhas: eram atores e criadores" (ALEKSIÉVITCH, 2016, p. 18).

Próxima dos pressupostos de Sarlo, Aleksiévitch parece ter criado um método próprio de investigação (HELLER; MARTINEZ, 2020) ao reconhecer que a história "está na rua. Na multidão. Acredito que em cada um de nós há um pedacinho da história. Um tem meia paginazinha, outro tem duas ou três. Juntos estamos escrevendo o livro do tempo" (ALEKSIÉVITCH, 2016, p, 19).

Eu sou Malala, por sua vez, é um relato integral em primeira pessoa, mas carece da leveza e da sensibilidade que exala em A guerra não tem rosto de mulher. Talvez por ter sido produzido sob encomenda e com o auxílio ininterrupto de uma jornalista profissional, a narrativa tenta cobrir, didaticamente, os eventos que culminaram no atentado sofrido pela protagonista. A inserção do mapa do Vale do Swat, no Paquistão, e seus arredores na página que antecede o Sumário é um indicativo do público a quem se dirige a obra.

Transformada lentamente em celebridade nacional por seu pai, diretor da escola onde estudava e com boas relações profissionais com outros educadores e jornalistas, Malala alcançou projeção internacional imediata após sofrer o atentado, em 2012. Ao receber o Prêmio Nobel da Paz em 2014, tornou-se ainda maior, apesar de sua pequena estatura, passando a ser a representação bem-sucedida da luta pela educação feminina em um contexto histórica e culturalmente marcado pela desigualdade de gênero.

Talvez esses elementos sejam suficientes para justificar por que consideramos a memória em Eu sou Malala mais enquadrada e social, do que subterrânea e individual. O que se encontra no livro corresponde às expectativas mais comerciais de uma casa editorial que projeta o produto final em função do interesse do público em geral. A midiatização da personagem, anterior ao livro, certamente contribuiu para esse formato de texto e, principalmente, da sua capa centrada, simétrica, objetiva.

Por outro lado, a estratégia de incorporar seu diário dentro do livro tensiona o jogo entre as memórias subterrânea e enquadrada. Subterrânea, porque se trata, afinal, de um relato em primeira pessoa que explicita a inexperiência da escrita da protagonista e seu temor em se tornar cada vez mais visível:

minha mãe começou a sentir medo de que eu andasse sozinha [...]. Eu não estava assustada, mas passei a verificar, à noite, se o portão estava mesmo trancado. E comecei a perguntar a Deus o que acontece quando a gente morre (YOUSAFZAI; LAMB, 2013, p. 14-15). 
Eu nunca tinha escrito um diário e não sabia como começar (YOUSAFZAI; LAMB, 2013, p. 164).

Se a condição do gênero feminino lhe impunha, pela cultura local, a impossibilidade de saber ler e escrever, ser autora de um livro poderia representar a materialização da contravenção da norma, o contradiscurso, o "subterrâneo". No entanto, como Malala trabalha com Christina Lamb, é possível que tenha moldado sua narrativa à expectativa da jornalista, confirmando as versões já divulgadas pelas diferentes mídias.

No prólogo do livro, o leitor depara-se com uma narrativa pessoal e potente: "Há um ano saí de casa para ir à escola e nunca mais voltei" (YOUSAFZAI; LAMB, 2013, p. 11). No entanto, o que se vê até o final da obra é o reforço de uma memória que já estava consolidada socialmente. A "garota" do início do livro ganha envergadura ao seu final, como é de se esperar de qualquer heroína que conta sua jornada. Bem-sucedida em todas as provas por que passa - vencer o preconceito de gênero, sobreviver a um atentado, superar as sequelas, emigrar e reunir a família em outro lugar - Malala corresponde à expectativa que os mitos constroem nas culturas: "retornar ao nosso meio, transfigurado, e ensinar a lição de vida renovada que aprendeu" (CAMPBELL, 2007, p. 372). Da mesma forma, a capa não seria diferente: mostrar a heroína com expressão firme, olhar direto ao leitor, sem a fragilidade dos sentimentos intensos. Uma mulher que parece saber o que quer e como lutar.

Já em Os diários de Berlim - 1940-1945, de Marie Vassiltchikov, reconhecemos o gênero textual diário, mas em função das interferências editoriais que sofreu, alargou seu sentido primeiro. Escrito espontaneamente por diversos anos, a autora relata seus medos, empregos, colegas de trabalho, estratégias de sobrevivência e, principalmente, a movimentação em torno do plano de assassinato de Adolph Hitler, conhecido por Operação Valquíria, em 20 de julho de 1944.

Inicialmente escritos apenas por um desejo pessoal e sem intenção de publicá-los, seus escritos foram retomados pela própria autora, depois da guerra, quando datilografou tudo novamente, incluindo trechos anotados em taquigrafia. Por mais de 25 anos a obra ficou guardada, mas, convencida a publicá-la em 1976 por seu irmão, “fez questão de cortar muito pouco do conteúdo e nada mudar de substancial. Todas as modificações se referiram à linguagem, ou ao trabalho comum de edição, ou ainda à troca de iniciais por nomes completos" (VASSILTCHIKOV, 2015, p, 19). A versão que conhecemos é a terceira e última, publicada pouco antes de sua morte. O projeto da capa da edição brasileira busca reconstruir visualmente algumas tensões do enredo. Ao mesmo tempo, ao serem utilizadas 
fotos aparentemente retiradas da imprensa - sem pose, com granulação e em baixa definição aproxima as imagens dos personagens às suas integridades históricas. Esse poder de contexto, de realidade e verdade, define personagens em ação dentro dos processos que construíram a narrativa.

O que interessa destacar aqui para a discussão proposta são as motivações da autora para alterar seu diário nas três versões. Assim como ocorreu em Eu sou Malala, a obra final tornou-se um livro de maior apelo comercial, o que explica os cortes e as inúmeras notas de rodapé de seu irmão e do tradutor.

A se acreditar no prefaciador, Marie Vassiltchikov escreve por necessidade para guardar as cenas que testemunhou, como se quisesse produzir uma obra memorialista, que perpetuasse sua identidade e a de sua família. Como esteve pessoalmente envolvida com a tentativa de exterminar Hitler, seu testemunho ganha credibilidade imediata, uma vez que não se encontram outros registros desse episódio com tais características. Tanto é assim que a obra foi publicada em diversos países e línguas. Na versão estadunidense, ganhou elogios do reconhecido romancista John Le Carré e, no Brasil, prefácio do tradutor Flávio Aguiar, discípulo de Antonio Candido, que também tem comentário na contracapa.

Os nomes da alta intelectualidade dos Estados Unidos e do Brasil que acompanham as diferentes edições de os Diários de Berlim endossam a boa qualidade do texto. Assim como em Eu sou Malala, reconhecemos na protagonista a figura da heroína, que abandona sua condição de aristocrata e seu país de origem três anos após a Revolução Russa, sobrevive à II Guerra Mundial em uma Berlim sob bombardeio e retorna à casa de seus parentes, ao final do conflito. A protagonista volta ao seu ponto de origem modificada, fortalecida e serve de exemplo às gerações seguintes.

Se, por um lado, não identificamos proximidade do tipo de testemunho entre Diários de Berlim e Eu sou Malala, por outro, é possível relacionar semelhanças das memórias ativadas pelas duas autoras russas, Aléksiévitch e Vassiltchikov: ambas escreveram sobre guerras e ativaram memórias "subterrâneas". No primeiro caso, de personagens anônimas e silenciadas; no segundo, de uma personagem ilustre, mas cujos diários guardavam detalhes até então jamais revelados.

\section{DE QUE GÊNERO DE TEXTO ESTAMOS FALANDO?}

Uma leitura atenta detectará nossa oscilação quando à classificação desses livros. $A$ guerra não tem rosto de mulher é jornalismo, literatura, jornalismo literário, memória ou 
história? Eu sou Malala é reportagem, diário, autobiografia, metadiário? E Diários de Berlim? Diário "que ultrapassa o gênero", autobiografia, história, literatura?

Philippe Lejeune (1975, p. 24) sugere que a autobiografia se caracteriza por ser "uma

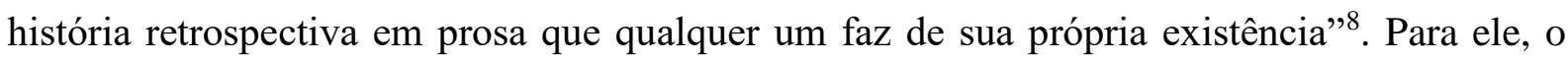
que diferencia esse gênero dos demais é o "pacto autobiográfico", a saber, o compromisso do autor com o leitor em dizer a verdade sobre si mesmo. Diferentemente da ficção, a autobiografia é referencial com fatos e contexto. Mas é também relacional:

o autobiógrafo coloca seu leitor em perigo. Ele lhe pede algo: reconhecimento, aprovação, amor. E, ao mesmo tempo, sugere ou propõe algo mais embaraçoso: a reciprocidade. O leitor é forçado a pensar em sua própria vida em termos análogos, mesmo se não tiver vontade de fazê-lo. A autobiografia é contagiosa e muitas pessoas têm medo dela (LEJEUNE apud NORONHA, 2002, p. 23).

Kelley Bapstista Duarte relata que esse termo apareceu a primeira vez no século XVIII, na Alemanha, mas até o final do século XX criaram-se outras categorias análogas, tais como epistolografia e diário íntimo (2010, p. 39).

Tal informação reforça o postulado de Tzvetan Todorov (1980, p. 46), para quem "um novo gênero é sempre a transformação de um ou de vários gêneros antigos: por inversão, por deslocamento, por combinação". Sendo assim, mais do que tentar classificar a que gênero pertencem os livros em análise, interessa-nos entender que suas narrativas são decorrentes de exercícios da memória de um "eu do passado" (quem escreveu) que não é o mesmo "eu do presente" (quem as lê). Decorre disso "que somente o relato das memórias em forma de diário poderia respeitar a verdade, posto que o registro se apresenta sob forma documental, de arquivo memorial datado" (DUARTE, 2010, p. 47).

Uma vez que "o direito de escrever sobre si pertence a todos" (LEJEUNE apud NORONHA, 2002, p. 24), o que muda entre os diversos gêneros aqui citados é o interesse que despertam nos leitores e a verdade que os leitores buscam neles. Já vimos com Beatriz Sarlo a importância conferida à subjetividade dos sujeitos, uma vez que contam suas verdades, instáveis por definição, pois estão atreladas à memória social e à individual. Para Lejeune, são as narrativas autobiográficas que adquirem estatuto de documento, uma vez que podem até ser usadas no campo jurídico, diferentemente dos diários. Pouco lidos por serem "invisíveis",

\footnotetext{
${ }^{8}$ No original: "récit rétrospectif en prose que quelqu'un fait de sa propre existance".
} 
raramente publicados, são muitas vezes destruídos por seus autores, exceto quando produzidos por "escritores interessantes" (LEJEUNE apud NORONHA, 2002, p. 24.).

Adotamos, portanto, como gênero diário, todos os textos que assim se autointitulam ou que narram experiências vividas e narradas em primeira pessoa sobre um tempo anterior ao da leitura. Não é de nosso interesse avaliar a fidelidade dos relatos em relação aos eventos, mas compreender as maneiras pelas quais vozes silenciadas produzem novos sentidos sobre a cultura. Transformadas em produtos comerciais por profissionais do mercado editorial, suas capas e contracapas, formas particulares da embalagem no consumo, veiculam imagens, comentários e várias articulações visuais que traduzem aspectos das narrativas, dos personagens e autores para a percepção do leitor.

\section{CONSIDERAÇÕES}

Nos três livros analisados vimos que as autoras testemunharam eventos traumáticos, que marcaram suas vidas. Diferentemente de Malala e de Marie Vassiltchikov, Svetlana Aleksiévitch não os viveu, mas os ouviu de centenas de mulheres que combateram no front, defendendo a então URSS contra os alemães nos anos 1940. Foi sua escuta cuidadosa que trouxe "a intransponível tragicidade da vida" (ALEKSIÉVITCH, 2016, p. 18) dessas mulheres silenciadas por 50 anos. Já as duas primeiras autoras experimentaram os eventos relatados e cumpriram a saga do herói. Malala sobrevive a um terrível atentado no Paquistão e, Marie Vassiltchikov, à II Guerra Mundial e à perseguição aos envolvidos na Operação Valquíria.

Ainda que o contexto das três autoras seja diverso, bem como as condições de escrita, consideramos que produziram diários enquanto gênero textual e que mobilizaram memórias não hegemônicas, exceto Malala, dada sua coautoria com uma jornalista e por ter sido resultado de obra contratada.

Cabe ao leitor atribuir o que é verdade, isto é, acreditar no relato como uma representação mais fiel possível aos fatos tais como ocorreram. Como teorizou Lejeune (1975), o "pacto autobiográfico" é determinante para que haja uma relação de verdade entre leitor e autor. Consideramos que o mesmo vale para os diários, ainda que tenham tido a interferência de diversos atores, como tradutores, organizadores, capistas, ilustradores, editores.

Reconhecer nos diários publicados por editoras comerciais um produto estéticocultural, não o torna menor, nem maior, mas certamente incentiva o interesse pelos relatos de 
seus autores que transformaram suas vidas e possivelmente de quem as lê. A contribuição deste artigo é perceber a importância cultural que tais narrativas trazem na contemporaneidade, especialmente em países cujas histórias subterrâneas costumam ser negadas ou silenciadas, como o nosso.

\section{REFERÊNCIAS}

ALEKSIÉVITCH, S. A guerra não tem rosto de mulher. S. Paulo: Companhia das Letras, 2016.

ARTIÈRES, P. Arquivar a própria vida. Estudos Históricos, Rio de Janeiro, v. 11, n. 21, p. 9-34, 1998.

CALDAS, S. Gabriela baiana de todas as cores: as imagens das capas e suas influências culturais. Salvador: EDUFBA, 2009.

CAMPBELL. J. O herói de mil faces. São Paulo: Cultrix/Pensamentos, 2007.

CARVALHO, A. A capa de livro: o objecto, o contexto, o processo. 2008.98 p. (Dissertação de Mestrado em Design) - Universidade do Porto, Porto, 2008.

DONDIS, D. A. Sintaxe da linguagem visual. 2. ed. São Paulo: Martins Fontes, 2003.

DUARTE, K. B. A escrita autoficcional de Régine Robin: mobilidades e desvios no registro da memória. 2010. 255 p. (Tese de Doutorado em Literatura) - UFRGS, Porto Alegre, 2010.

HELLER, B.; MARTINEZ, M. A guerra não tem rosto de mulher: Svetlana Aleksiévitch reescreve a Segunda Guerra Mundial. São Paulo: E-Compós, Brasília, n. 23, 2020. Versão Ahead of print. Disponível em: https://www.e-compos.org.br/e-compos/article/view/1990/1980

LEJEUNE, P. Le pacte autobiographique. Paris: Seuil, 1975.

McCRAKEN, G. Cultura e consumo: novas abordagens ao caráter simbólico dos bens e das atividades de consumo. Rio de Janeiro: Mauad, 2003.

NORONHA, J. M. G. Entrevista com Philippe Lejeune. Ipotesi, Juiz de Fora, v. 6, n. 2, p. 21-30, 2002.

PERALTA, E. Abordagens teóricas ao estudo da memória social: uma resenha crítica. Revista Arquivos da Memória, Lisboa, n. 2, p. 4-23, 2007.

POLLAK, M. Memória, esquecimento, silêncio. Estudos Históricos, Rio de Janeiro, v. 2, n. 3, p. 3-15 1989.

SARLO, B. Tempo passado: cultura da memória e guinada subjetiva. São Paulo: Companhia das Letras, 2007.

SELIGMANN-SILVA, M. Narrar o trauma - a questão dos testemunhos de catástrofes históricas. Psicologia Clínica, Rio de Janeiro, v. 20, n. 1, p. 65-82, 2008. 
SELIGMANN-SILVA, M. Testemunho e a política da memória: o tempo depois das catástrofes. Projeto História, São Paulo, n. 30, p. 71-98, 2005.

TODOROV, T. Os gêneros do discurso. São Paulo: Martins Fontes, 1980.

YOUSAFZAI, M.; LAMB, C. Eu sou Malala - a história da garota que defendeu o direito à educação e foi baleada pelo Talibã. São Paulo: Companhia das Letras, 2013.

VASSILTCHIKOV, M. Diários de Berlim - 1940-1945: os bastidores da operação que planejou assassinar Hitler. São Paulo: Boitempo, 2015.

Original recebido em: 23 de maio de 2020

Aceito para publicação em: 23 de outubro de 2020

\section{Barbara Heller}

Possui graduação em Teoria Literária pela Universidade Estadual de Campinas (1982), mestrado em Ciências da Comunicação pela Universidade de São Paulo (1990) e doutorado em Teoria Literária pela

Universidade Estadual de Campinas (1997). É pós-doutorada em Comunicação pela Universidade Metodista (2011), sob a supervisão do Prof. Dr. Laan Mendes de Barro e pela Escola de Comunicação e Artes da Usp (2015), sob a supervisão da profa. Dra. Maria Cristina Castilho Costa. Atualmente é docente e vice-coordenadora do Programa de Mestrado e Doutorado em Comunicação da

Universidade Paulista (Unip). É líder do Grupo de Pesquisa Narrativas da Memória: Representações, Identidades e Culturas, cadastrado no diretório do CNPq, e membro fundadora da rede de pesquisa Rememora. Foi fundadora, vice-coordenadora e coordenadora do Grupo de Trabalho Memória nas Mídias, da Associação dos Programas de Pós-Graduação em Comunicação (Compós), de 2015 a 2017.

Tem experiência na área de comunicação e literatura, com ênfase nos seguintes temas: estudos de gênero, censura, memória, leitura, mídia impressa.

Herom Vargas

Docente pesquisador do Programa de Pós-Graduação em Comunicação Social (PósCom) da Universidade Metodista de São Paulo (UMESP) desde 2016. Foi docente do Programa de PósGraduação em Comunicação da Universidade Municipal de S. Caetano do Sul (USCS), de 2008 a 2015, tendo coordenado o Programa entre 2013 e 2015. Possui graduação em História pela Pontifícia Universidade Católica de São Paulo (1987), mestrado (1994) e doutorado (2003) em Comunicação e Semiótica também pela PUC-SP e pós-doutorado em Comunicação pela ECA-USP (2015). Foi membro da diretoria da seção latino-americana da International Association for Study of Popular Music (IASPM-AL) como editor (2012-2014) e como vice-presidente (2014-2016). É autor do livro

Hibridismos Musicais de Chico Science \& Nação Zumbi (Ateliê Editorial, 2007) e organizador de outros quatro livros. É líder do grupo de pesquisa Mídia, Arte e Cultura - MAC (CNPq), no PósCom da UMESP. Tem capítulos de livro e artigos em diversas revistas acadêmicas e pesquisas envolvendo os seguintes temas: música popular, música e comunicação, estéticas e linguagens midiáticas e memória nas mídias. 


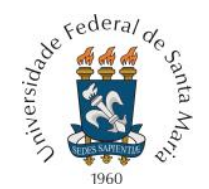

PROGRAMA DE PÓS-GRADUAÇÃO EM COMUNICAÇÃO DA UNIVERSIDADE FEDERAL DE SANTA MARIA

\section{(C) $(\Theta \odot$}

Esta obra está licenciada com uma Licença

Creative Commons Atribuição-NãoComercial-CompartilhaIgual 4.0 Internacional 